\title{
Radiological findings of uterine arteriovenous malformation: a case report of an unusual and life-threatening cause of abnormal vaginal bleeding"
}

\author{
Aspectos radiológicos da malformação arteriovenosa uterina: relato de caso de uma causa \\ incomum e perigosa de sangramento vaginal anormal
}

\section{Marcela Sales Farias ${ }^{1}$, Clara Campagnaro Santi ${ }^{1}$, Aline Aparecida A. de A. Lima ${ }^{2}$, Sabrina Mendes Teixeira ${ }^{3}$, Tatiana Co Gomes De Biase ${ }^{4}$}

Farias MS, Santi CC, Lima AAAA, Teixeira SM, De Biase TCG. Radiological findings of uterine arteriovenous malformation: a case report of an unusual and life-threatening cause of abnormal vaginal bleeding. Radiol Bras. 2014 Mar/Abr;47(2):122-124.

Abstract Uterine arteriovenous malformations may cause life-threatening abnormal genital bleeding in women at childbearing age. Transvaginal Doppler ultrasonography is a widely available, noninvasive and excellent diagnostic method. The authors report the case of a patient with history of gestational trophoblastic disease and multiple curettage procedures who developed uterine arteriovenous malformations, with remission of the lesions after treatment with methotrexate.

Keywords: Arteriovenous malformations; Doppler; Abnormal genital bleeding.

Resu mo Malformações arteriovenosas uterinas podem causar sangramento genital anormal, representando risco de morte nas mulheres em idade reprodutiva. O ultrassom transvaginal com Doppler é um método não invasivo amplamente disponível e excelente ferramenta diagnóstica. Apresentamos o caso de paciente com história de doença trofoblástica gestacional e múltiplas curetagens que evoluiu com malformações arteriovenosas uterinas, apresentando remissão das lesões após tratamento com metotrexate.

Unitermos: Malformações arteriovenosas; Doppler; Sangramento genital anormal.

\section{INTRODUCTION}

Uterine arteriovenous malformation (AVM) is a rare vascular condition, with less than 100 cases reported in the literature. It is a dilatation of the intervillous space deep inside the myometrium, allowing a direct flow from the arterial system towards the venous system, without participation of capillary vessels ${ }^{(1)}$. Such condition represents about $1-$ $2 \%$ of all genital and intraperitoneal hemorrhages ${ }^{(2)}$.

Uterine AVMs may be either congenital or acquired. The congenital presentation is rarely found, resulting from abnormal embryonic development of the primitive vascular

* Study developed at Hospital Universitário Cassiano Antonio Moraes (Hucam) Universidade Federal do Espírito Santo (UFES), Vitória, ES, Brazil.

1. MDs, Residents of Radiology and Imaging Diagnosis, Universidade Federal do Espírito Santo (UFES) / Hospital Universitário Cassiano Antonio Moraes (Hucam), Vitória, ES, Brazil.

2. MD, Resident of Gynecology and Obstetrics, Universidade Federal do Espírito Santo (UFES) / Hospital Universitário Cassiano Antonio Moraes (Hucam), Vitória, ES, Brazil.

3. MD, Gynecologist and Obstetrician, Resident of Ultrasonography in Gynecology and Obstetrics, Universidade Federal do Espírito Santo (UFES) / Hospital Universitário Cassiano Antonio Moraes (Hucam), Vitória, ES, Brazil.

4. MD, Gynecologist and Sonographer, Preceptor of Ultrasonography in Gynecology and Obstetrics and Radiology and Imaging Diagnosis, Universidade Federal do Espírito Santo (UFES) / Hospital Universitário Cassiano Antonio Moraes (Hucam), Vitória, ES, Brazil.

Mailing Address: Dra. Marcela Sales Farias. Rua Doutor Delmiro Coimbra, 80, cobertura 2A, Mata da Praia. Vitória, ES, Brazil, 29065-360. E-mail: lelasf@gmail.com.

Received September 24, 2012. Accepted after revision July 22, 2013. structures which determine multiple abnormal communications between arteries and veins ${ }^{(3)}$. However, in most cases such malformation is acquired, with a great variety of causes, including gestational trophoblastic disease (GTD), pelvic trauma, surgical procedures (cesarean section, curettage), cervical or endometrial carcinoma, infection and exposure to diethylstilbestrol ${ }^{(4,5)}$. The association of the clinical history with imaging findings is useful in the differentiation between congenital and acquired presentations.

\section{CASE REPORT}

An 18-year-old patient found out to be pregnant and, one month later, presented with abnormal genital bleeding. Ultrasonography (US) results were suggestive of GTD. The patient underwent three curettages, maintaining high betaHCG levels $(34,818.00)$, with diagnosis of GTD. Transvaginal US demonstrated the presence of myometrial arteriovenous fistulas and tamponade of the communication between the uterine cavity and the serosa (a sequela from perforation during a previous curettage).

Five months after the symptoms onset, the patients remained with high beta-HCG levels, so treatment with methotrexate was initiated. The patients underwent a new US whose findings were similar to those observed on the previous study (Figures 1, 2 and 3). Pelvic magnetic resonance imaging (MRI) confirmed the presence of arteriovenous fistulas (Figure 4). 


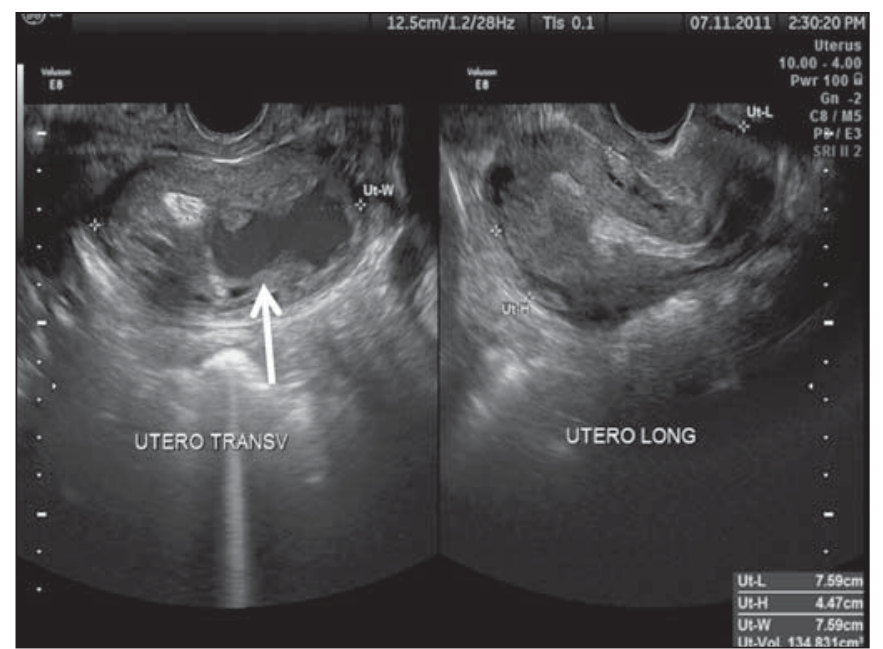

Figure 1. Gray scale transvaginal US demonstrating uterus increased in volume with heterogeneous myometrial echotexture due to the presence of multiple anechoic images. The largest of such images is located on the left lateral wall (arrow).
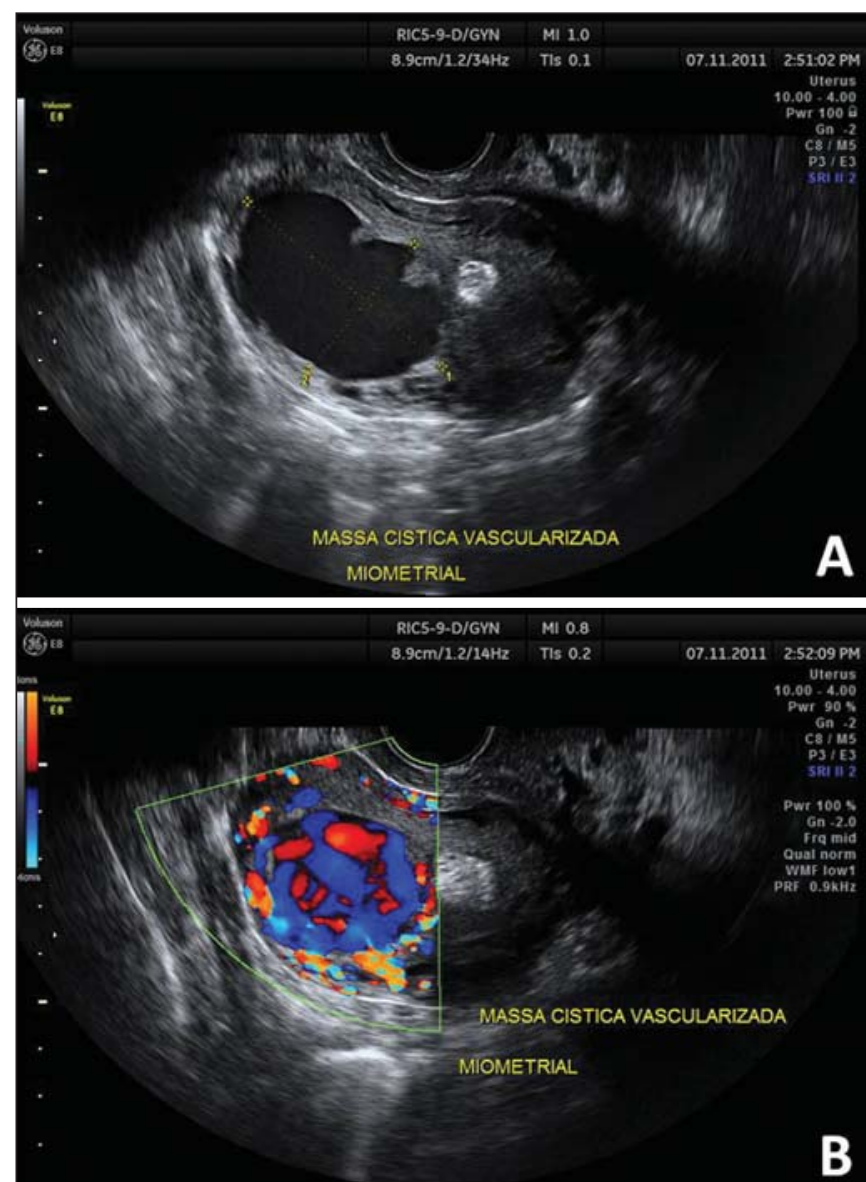

Figure 2. Gray scale transvaginal US demonstrating the presence of a large, anechoic, intramyometrial mass (A). Color Doppler study demonstrated turbulent flow within the mass (B).

A good response to monochemotherapy was observed, and the patient presented negative serum beta-HCG levels within seven months. Follow-up US after the treatment demonstrated the uterus with normal volume, presence of small amount of fluid in the uterine cavity and hematosalpinx. The arteriovenous fistulas did not exist anymore.

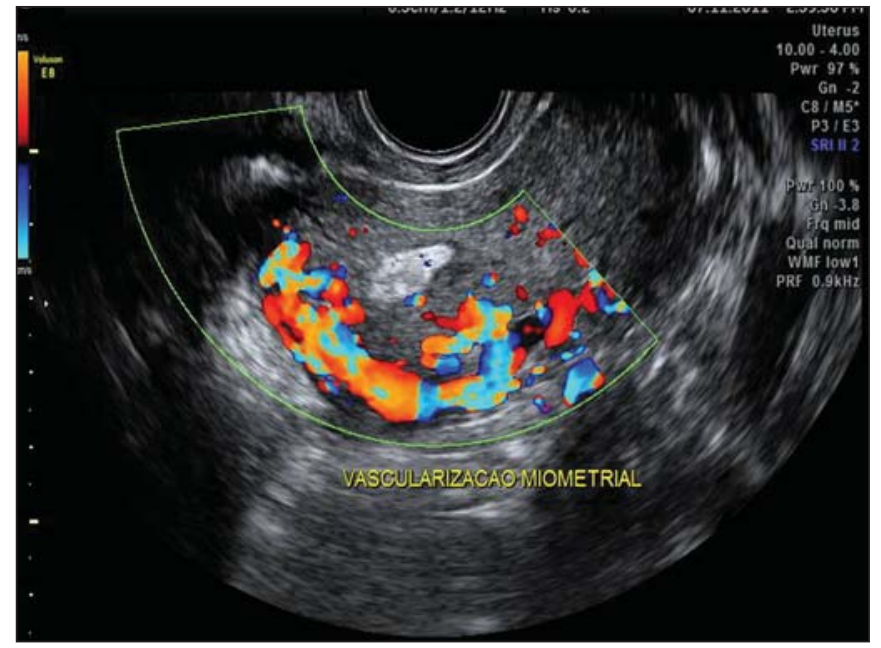

Figure 3. Transvaginal color Doppler US demonstrating intense myometrial hypervascularization with turbulent flow.
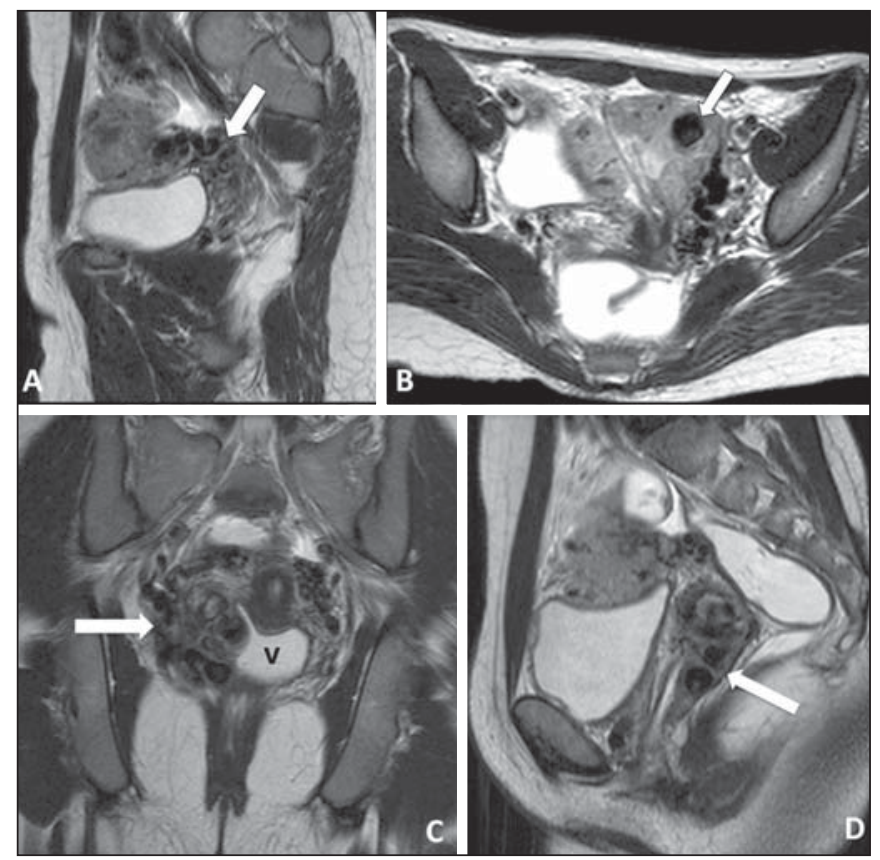

Figure 4. Pelvic MRI - sagittal (A, D), axial (B) and coronal (C), T2-weighted TSE sequences. The images show the uterus increased in volume, with multiple vascular-like serpiginous structures characterized by flow void (arrow on A). In the fundus/left lateral wall of the uterus, a round-shaped lesion with similar characteristics corresponding to a voluminous arteriovenous fistula (arrow on B). Also, the presence of prominent parametrial vessels is observed at right (arrows on $\mathbf{C}$ and D). V, vaginal cavity distended by gel.

Three months after the negative beta-HCG results, the patient presented increased serum beta-HCG levels again and polychemotherapy was initiated, but she died because of septic complications.

\section{DISCUSSION}

Acquired uterine AVMs are abnormal communications between intramural branches of the uterine artery and the myometrial venous plexus, deep inside the myometrium and endometrium. They may be supplied by one or both uterine 
arteries, without blood supply from extrauterine or interposition of a vascular plexus. Causes include curettage and GTD, and AVMs persist in 10-15\% of cases of GTD in remission after chemotherapy.

Generally, such lesions occur in women at childbearing age, with either acute or chronic symptoms ${ }^{(2,6)}$. The most common symptom is menorrhagia or menometrorrhagia. Other symptoms include recurrent spontaneous miscarriages, low abdominal pain, dyspareunia and anemia secondary to blood loss. Pelvic assessment can demonstrate a pulsatile mass $^{(2,4)}$. It is believed that the bleeding occurs as the malformation vessels become exposed due to the endometrial desquamation during menstruation, or iatrogenically during dilatation and curettage ${ }^{(6)}$.

Historically, the diagnosis was made after laparotomy. Subsequently, angiography became the gold standard. Currently, transvaginal Doppler US is the most utilized method, and angiography is reserved for patients submitted to surgical treatment or therapeutic embolization ${ }^{(4)}$.

US findings include heterogeneous, ill-defined mass, with multiple, hypoechoic cystic or tubuliform structures varying in size and focal or asymmetrical endometrial and myometrial thickening. Doppler US demonstrates arteriovenous shunt with low-resistance and high-velocity flow. Spectral analysis may predict the degree of the vascular lesion arterializations and aid in the definition of the treatment ${ }^{(3)}$.

Although Doppler US can strongly suggest the presence of AVM, its ability to accurately determine the lesion extent in the pelvis may be limited. MRI is an excellent noninvasive method to determine the disease extent and aid to confirm the diagnosis ${ }^{(6)}$. Findings include voluminous uterus, illdefined mass, focal or diffuse interruption of the junctional zone and prominent parametrial vessels ${ }^{(2)}$.

Differential diagnoses with similar sonographic findings include GTD and other hypervascular lesions such as retained conception products and abnormal placentation ${ }^{(2)}$. Such a differentiation is critical, considering that curettage is not the appropriate therapy in cases of AVM and might exacerbate the bleeding ${ }^{(7)}$. Stable patients may be conservatively treated, with spontaneous lesion regression. Therapeutic embolization is indicated in cases of anemic or hemodynamically instable patients ${ }^{(2,7)}$.

Uterine AVMs are uncommon lesions, but may be cause of severe genital bleeding ${ }^{(2)}$. Such a diagnosis should be considered in patients at childbearing age with history of uterine instrumentation or other risk factors (such as GTD) who present with abnormal genital bleeding. Doppler US is an excellent noninvasive and widely available diagnostic method, but the knowledge about this clinical entity is essential, despite its rarity.

\section{REFERENCES}

1. Belfort P, Braga A, Freire NS. Malformação arteriovenosa uterina após doença trofoblástica gestacional. Rev Bras Ginecol Obstet. 2006;28:112-21.

2. Cura M, Martinez N, Cura A, et al. Arteriovenous malformations of the uterus. Acta Radiol. 2009;50:823-9.

3. O'Brien P, Neyastani A, Buckley AR, et al. Uterine arteriovenous malformations: from diagnosis to treatment. J Ultrasound Med. 2006;25:1387-92; quiz 1394-5.

4. Timmerman D, Wauters J, Van Calenbergh S, et al. Color Doppler imaging is a valuable tool for the diagnosis and management of uterine vascular malformations. Ultrasound Obstet Gynecol. 2003;2 1: $570-7$.

5. Meilstrup JW, Fisher ME. Women's health case of the day. Uterine arteriovenous malformation. AJR Am J Roentgenol. 1994;162:14578.

6. Huang MW, Muradali D, Thurston WA, et al. Uterine arteriovenous malformations: gray-scale and Doppler US features with MR imaging correlation. Radiology. 1998;206:115-23.

7. Poli-Neto OB, Víbrio Neto JB, Nogueira AA, et al. Embolização arterial seletiva em fístula arteriovenosa uterina pós-traumática. Radiol Bras. 2004;37:303-5. 